\title{
低温灰化装置による食用油の前処理
}

(昭和 51 年 6 月 15 日受理)

田村征男 ${ }^{* 1}$ 石原利克*1 森山繁隆*2

\section{Studies on Conditions of Pretreatment with a Plasma Systems for Determination of Heavy Metals in Edible Oil}

\author{
Yukio TAMURA*1, Toshikatsu IshIHARA*1 and Shigetaka MorIYAMA*2 \\ ( ${ }^{* 1}$ Nagoya City Health Research Institute: 1-11, Hagiyama-cho, Mizuho-ku, Nagoya; \\ *2Nagoya Municipal Dietitian School: 1-11, Hagiyama-cho, Mizuho-ku, Nagoya)
}

For the determination of heavy metals in edible oil with atomic absorption method, an effective technique with a low tempereture asher using the oxygen plasma have not been established.

When some oils were tried to be ashed, they were easily polymerized to become resin form, and ashing time need for a month.

In order to reduce the ashing time, some additives which serve as intermediate to enlarge oil surface and as catalyst for oxidation were examined.

In the case of addition of agar or cornstarch to oil, oil became spongy form and ashing was completed within about $48 \mathrm{hr}$.

But agar was not suitable for the analytical purpose with the atomic absorption method on account of the presence of heavy metals contaminant.

Therefore cornstarch was most suitable ashing agent, when food oil was ashed with a plasma system.

(Received June 15, 1976)

\section{1. 緒言}

最近食用油脂を多量に含有する食品および洗剂中の有 害性金属を分析する機会が多く，その金属の種類は，七 素，鉛，銅，カドミウム，スズ，クロムなどである.

金属の分析漈し，試験溶液の調製は，従来から硫硝

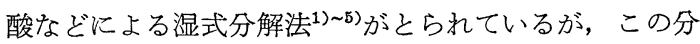
解法は，油脂の分解には長時間を要し，かつ酸の消費が多 いため, ブランク值は大きくなり過量の鉱酸による妨害

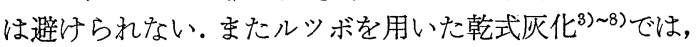
当然七素, スズの分析は不能である.これらの理由から 金属の損失の少ない低温灰化法を採用し，灰化促進のた めの添加剤の効果について検討した結果, 試料の油脂に コーンスターチを添加することにより所期の目的を達す ることができたので報告する.

*1 名古屋市衛生研究所：名古屋市瑞穂区萩山町 1-11

*2 名古屋市栄養専門学院：名古屋市瑞穂区萩山町 1-11

\section{2. 試薬および装置}

2.1. 試薬

硝酸, 塩酸（片山化学 (株) 製精密分析用)，ゴマサラ ダ油 (竹本油脂(株)製)、 コーンスターチ（日本食品化 工(株)製)，バレイショデンプン，コムギデンプン，グ ルコース, ショ糖, デキストリン, 可溶性デンプン (以 上片山化学 (株)製 EP), 寒天 (Difco Bacto Agar), CMC N-300 (片山化学(株)製 EP)，ポリアミド (Welm クロマト用), 微結晶セルロース (アビセル, アビセル S F), ゼラチン (片山化学(株)製 E P), クロモンルブ G (AW-DMCS 60 80 mesh), グラスビーズ (Corning GLC 110)，アルミナ (Welm neutral), シリカゲル (和 光純薬(株) 製 $\mathrm{Q} 23)$.

\section{2. 回収実験用標準溶液}

鉛標準溶液：硝酸鉛 $159.8 \mathrm{mg}$ を希硝酸 $10 \mathrm{ml}$ に溶 かし，水を加えて $1000 \mathrm{ml}$ とする，この液 $1 \mathrm{ml}$ は, $\mathrm{Pb}$ $100 \mu \mathrm{g}$ を含む.

七素標準溶液：食品添加物公定書による標準原液を調 
製し，この液 $10 \mathrm{ml}$ をとり，水を加えて $100 \mathrm{ml}$ とす る.この液 $1 \mathrm{ml}$ は As $10 \mu \mathrm{g}$ を含む.

スズ標準溶液：金属スズ $100.0 \mathrm{mg}$ に塩酸 $20 \mathrm{ml}$ を加 え, 時計血で覆い水浴上で加熱して溶かし $1 N$ 塩酸で $1000 \mathrm{ml}$ とする. この液 $1 \mathrm{ml}$ は Sn $100 \mu \mathrm{g}$ を含む.

ジブチルスズ標準溶液: ジブチルスズクロライド $100.0 \mathrm{mg}$ をエチルアルコールに溶かして $1000 \mathrm{ml}$ とす る.この液 $1 \mathrm{ml}$ は, Sn $39.1 \mu \mathrm{g}$ を含む.

ジオクチルスズ標準溶液; ジオクチルスズクロライド $102.7 \mathrm{mg}$ を土チルアルコールに溶かして $1000 \mathrm{ml}$ とす

\section{る.この液 $1 \mathrm{ml}$ は, $\mathrm{Sn} 29.3 \mu \mathrm{g}$.を含む.}

\section{3. 装置}

低温灰化装置: IPC 社製 1005B B48型

原子吸光分光光度計：(株) 日立製作所製 207 型 ポーラログラフ：(株) 柳本製作所製 P-8 型

\section{3. 実験方法および結果}

\section{1. 灰化条件の検討}

低温灰化装置は，高周波出力を 1 チャンバー当たり 150W まで上げることができる. しかし，この条件に設 定すると試料の灰化は短時間で完了できるが，高温にす るなどのより高いエネルギーを与える結果, ヒ素の揮散 などによる損失は免れない，そこで装置の運転条件検討 のため, 七素 $10 \mu \mathrm{g}$ ，スズ $50 \mu \mathrm{g}$ ，鉛 $50 \mu \mathrm{g}$ に相当する 各標準液を，それぞれ専用試料血（径 $6 \mathrm{~cm}$ ) にとり，水 浴上で蒸発乾固した後チャンバーに入れ，高周波出力を $12.5 ， 25 ， 37.5 ， 50 \mathrm{~W}$ 設定して各々 48 時間処理した後 試料血を取り出し, 希硝酸 $2 \mathrm{ml}$ を加えて内容物を溶解 し, 水浴上で蒸発乾固した後, $1 N$ 塩酸で $10 \mathrm{ml}$ とし試 験溶液とした。 七素はグートッアイト法，スズはポーラ ログラフ法，鉛は原子吸光法で測定し，その結果を Table 1 に示す.

出力を 50 Wにした場合でも鉛は良好な回収率を示した が，七素とスズは $37.5 \mathrm{~W}$ でも非常に低い值を示したの で，七素やスズを含む油の灰化には，高周波出力をすべ て $25 \mathrm{~W}$ 以下で操作することに決定した.

\section{2. 油の灰化}

油脂試料 $5 \mathrm{~g}$ を専用試料血に科取し，水分を含有して いる場合は，凍結乾燥によってこれを除いた後，チャン バーに入れ出力 $25 \mathrm{~W}$ で灰化させると, 寸ぐ灰化反応が 始まるが 2 3 時間で反応しなくなる.このとき試料皿

Table 1. Recovery of $\mathrm{Pb}, \mathrm{Sn}, \mathrm{As}$ on Plasma Ashing

\begin{tabular}{r|r|r|r|r}
\multirow{2}{*}{ Metal } & \multicolumn{4}{|c}{ Recovery (\%) } \\
\cline { 2 - 5 } & $12.5 \mathrm{~W}$ & \multicolumn{1}{|c}{$25.0 \mathrm{~W}$} & $37.5 \mathrm{~W}$ & $50.0 \mathrm{~W}$ \\
\hline $\mathrm{Pb}$ & $100.0 \pm 0.2$ & $100.0 \pm 0.2$ & $100.0 \pm 0.4$ & $98.6 \pm 0.4$ \\
$\mathrm{Sn}$ & $92.0 \pm 1.5$ & $90.0 \pm 1.3$ & $72.8 \pm 1.8$ & $50.8 \pm 0.9$ \\
$\mathrm{As}$ & $95.0 \pm 2.7$ & $95.0 \pm 2.2$ & $54.0 \pm 4.9$ & $31.0 \pm 2.4$
\end{tabular}

Table 2. Ashing Time of Sesame Oil Contained of Various Additives

\begin{tabular}{l|c|c}
\multicolumn{1}{c|}{ Additives (5 g) } & Oil (5g) & Time (hours) \\
\hline Corn starch & Sesame oil & 48 \\
Potato starch & " & 64 \\
Wheat starch & " & 64 \\
Soluble starch & " & $96<$ \\
Dextrin & " & 64 \\
Glucose & impossible \\
Sucrose & " & impossible \\
Agar & " & 36 \\
Casein & " & $96<$ \\
CMC & " & $96<$ \\
Polyamide & " & 60 \\
Cellulose powder & " & $96<$ \\
Gelatin & " & $96<$ \\
Chromosorb G & " & $96<$ \\
Glass beads & " & $96<$ \\
Alumina & " & $96<$ \\
Silicagel & &
\end{tabular}

を取り出してみると無臭になっており，油の表面は酸化 重合して樹脂化が始まっている. これを添付した小ガラ ス棒でかきまぜて新しい表面を出し，再び灰化を続け る.このように毎日新しい表面を出す操作を繰り返しな がら反応させても完全に灰化するには，1か月間を要し た.

\section{3. 添加剂の検討}

試料皿に油のみを入れた場合には，その灰化に長時間 を要するにもかかわらず, 他の食品, 特に脂肪の多い魚 のすり身（脂肪約 $20 \%$ ） $10 \mathrm{~g}$ を秤取し凍結乾燥した後, 出力 $25 W て ゙$ 灰化した場合に，48時間で完了している. ま た不純物が共存する場合に, 飽和脂肪酸の酸化が促進さ れるという Brodnitz" ${ }^{9)} ら の$ 報告があることから, 油の 灰化時間の短縮は表面積の増大と, 酸化促進への触媒効 果をもたらす添加剤が必要である. そこで扊化を促進す る添加剤としてガラスビーズはじめ無機質 4 種類, コー ンスターチはじめ有機質14種類について検討した. 油 $5 \mathrm{~g}$ を科取した試料血に, これら添加剂 $5 \mathrm{~g}$ を加え, 添付し た小ガラス棒でよくかきまぜた後, 灰化を行った結果を Table 2 に示す.

ガラスビーズ添加の場合は, 油のみを灰化した場合と 同様に反応は一時的に止まり，その後は酸化重合して樹 脂化が始まる結果, 粘度が高まった油がガラスビーズの 表面を覆い，その粘性のために個々のガラスビーズが付 着し合って固まり，灰化は96時間以上を要した。 またシ リカゲル，クロモソルブ G，アルミナも同様な結果であ り，ぞの場合も固結して96時間以上を要した。

有機質添加剤としてコーンスターチを油 $5 \mathrm{~g}$ に添加 
Table 3. Heavy Metal Content of Additives

\begin{tabular}{|c|c|c|c|c|c|c|c|}
\hline Additives & $\underset{(\mathrm{ppm})}{\mathrm{Pb}}$ & $\underset{(\mathrm{ppm})}{\mathrm{Cd}}$ & $\underset{(\mathrm{ppm})}{\mathrm{Cu}}$ & $\underset{(\mathrm{ppm})}{\mathrm{Zn}}$ & $\underset{(\mathrm{ppm})}{\mathrm{Mn}}$ & $\underset{(\mathrm{ppm})}{\mathrm{As}}$ & \\
\hline Corn starch & $\mathrm{ND}^{*}$ & ND & 0.07 & 0.24 & 0.07 & ND & \\
\hline Potato starch & ND & ND & 0.26 & 0.40 & 0.40 & $\mathrm{ND}$ & \\
\hline Soluble starch & 0.33 & ND & 1.03 & 1.20 & 1.56 & $\mathrm{ND}$ & \\
\hline Dextrin & 0.25 & ND & 3.13 & 1.95 & 0.45 & ND & \\
\hline Agar & 0.90 & 0.16 & 0.42 & 5.80 & 0.19 & ND & $\begin{array}{l}\mathrm{Ca} 2100 \mathrm{ppm} \\
\mathrm{Mg} 1160 \mathrm{ppm}\end{array}$ \\
\hline Polyamide & 0.38 & ND & 0.22 & 18.3 & 0.06 & $\mathrm{ND}$ & $\mathrm{Ca} \quad 564 \mathrm{ppm}$ \\
\hline Cellulose powder (thin layer) & 0.23 & ND & 0.10 & 0.46 & 0.05 & $\mathrm{ND}$ & \\
\hline Cellulose powder (column) & ND & ND & 0.06 & 0.21 & ND & ND & \\
\hline Gelatin & 0.52 & ND & 0.31 & 0.88 & 97.0 & $\mathrm{ND}$ & \\
\hline Chromosorb G & 0.31 & ND & 0.10 & 0.60 & 0.23 & $\mathrm{ND}$ & \\
\hline
\end{tabular}

し，小ガラス棒でよく混ぜて白いのり状とした後，チャ ンバーに入れ減圧にすると，混合時に混入した空気の放 出のために，油全体が盛り上がるので，あふれ出たり飛 び散らせないように一時圧をあげるなど慎重に減圧とし た後, 初め出力を $10 \mathrm{~W}$, 酸素流量毎分 $10 \mathrm{ml}$ で約 1 時 間続けた後, 出力 $25 \mathrm{~W}$, 酸素流量毎分 $25 \mathrm{ml}$ まで上げ る. 約 8 時間後取り出してみると表面は樹脂化して薄い 被膜となり，内部はスポソジ状に底の未反応部分は，わ ずかにのり状を呈している．これを小ガラス棒を用いて できるだけ細かく砕いた後，さらに続けるとスポンジ状 のまま表面から灰化が始まり，常に新しい表面を出しな がら後退して少量になり，約48時間後に試料血の中は， 淡青色のほこり様の灰を残して完了した.

同じデンプンではあるが，バレイショ，コムギ，デキ ストリンを用いた場合には，油と分離しやすく，表面の 油層のみ反応してスポンジ状になるまでに長時間を要 し，灰化完了に64時間を要した。 また可溶性デンプンを 用いた場合には，スポンジ状となってから，そのまま黒 褐色に炭化するの及で扊化は困難であり96時間以上を要 した。 また比較的低分子量のグルコース，ショ糖などに あっては，全体がカラメル状態となりながら盛り上が り，灰化は不能であった。一方寒天では，油を吸収して 増量し始めから良好なスポンジ状となり，クロマト用の ポリアミドも寒天ほど增量しないが同様に良好なスポン ジ状となり，ともに表面の灰化反応は急速であり 36 時間 で完了した。またセルロース（アビセル）では，初めか らスポンジ状となったが灰化速度は遅く 60 時間を要し た。 CMC，培地用ゼラチンでは，ともにスポンジ状にな りにくく，乙かも灰化が困難であり長時間を要した。

\section{4. 添加剤中の金属含量の検討}

一般に食用油中の金属含量は微量であり，これに比較 して扊化時の添加剤より混入する金属量は無視できない ので, 各添加剂 $5 \mathrm{~g}$ を同条件で灰化し, 同じ操作を行っ
て試験溶液として金属量を測定した結果を Table 3 に示 す. 灰化時, 良好な結果を示した寒天では, カルシウ ム，マグネシウムおよび重金属類の含量が多く, 添加剤 として不適当である. またポリアミドもカルシウム，亜 鉛，鉛などの含量が多いがヒ素の定量に限定すれば，使 用可能と思われる.

これらに比して, コーンスターチは, 鉛, カドミウ ム，七素を含まず，検討した添加片のうちでは最も合目 的なものであった。

\section{5. 添加回収実験}

チャンバー当り出力 $25 \mathrm{~W}$, 酸素流量毎分 $25 \mathrm{ml}$ の灰化 条件で，油 $5 \mathrm{~g}$ に七素 $10 \mu \mathrm{g}$ をはじめ他の金属一定量ず つを添加し，コーンスターチ $5 \mathrm{~g}$ を混入して処理した後 測定した. 回収率は, Table 4 に示すよう飞鉛100,1\%, 七素96.3\%，スズ89.8\%であり，特に有機スズ（ジブチ ルスズクロライド，ジオクチルスズクロライド) で添加 した場合でも，それぞれ $86.8 \% ， 95.1 \%$ と良い結果であ った。

\section{4. 各種油中の金属含量}

食用油 9 種類の分析例を Table 5 亿示す。綿実油抒

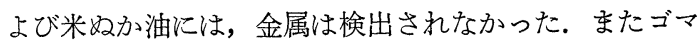
油では，その精製条件の違いから，銅，マンガン，亜鉛

Table 4. Recovery of $\mathrm{Pb}, \mathrm{As}, \mathrm{Sn}$ Added to Oil by Plasma Ashing

\begin{tabular}{c|c|c|c} 
Metal & Added $(\mu \mathrm{g})$ & Found $(\mu \mathrm{g})$ & $\begin{array}{c}\text { Recovery } \\
(\%)\end{array}$ \\
\hline $\mathrm{Pb}$ & 50.0 & 50.1 & $100.1 \pm 0.2$ \\
$\mathrm{As}$ & 10.0 & 9.63 & $96.3 \pm 2.2$ \\
$\mathrm{Sn}$ & 50.0 & 44.9 & $89.8 \pm 1.3$ \\
Dibutyl Sn & $78.2^{*}$ & 67.9 & $86.8 \pm 2.2$ \\
Dioctyl Sn & $58.6^{*}$ & 55.7 & $95.1 \pm 0.9$
\end{tabular}

* inorganic $\mathrm{Sn}$ 
Table 5. Heavy Metal Content in Oils

\begin{tabular}{|c|c|c|c|c|c|c|c|c|c|}
\hline \multicolumn{2}{|l|}{ Sample } & $\underset{(\mathrm{ppm})}{\mathrm{Pb}}$ & $\underset{(\mathrm{ppm})}{\mathrm{Cd}}$ & $\underset{(\mathrm{ppm})}{\mathrm{Cu}}$ & $\underset{(\mathrm{ppm})}{\mathrm{Mn}}$ & $\underset{(\mathrm{ppm})}{\mathrm{Cr}}$ & $\underset{(\mathrm{ppm})}{\mathrm{Zn}}$ & $\underset{(\mathrm{ppm})}{\mathrm{As}}$ & $\underset{(\mathrm{ppm})}{\mathrm{Fe}}$ \\
\hline \multicolumn{2}{|c|}{ Cottonseed oil } & $\mathrm{ND}^{*}$ & ND & ND & ND & ND & ND & ND & ND \\
\hline \multicolumn{2}{|c|}{ Lice bran oil } & $\mathrm{ND}$ & $\mathrm{ND}$ & $\mathrm{ND}$ & $\mathrm{ND}$ & $\mathrm{ND}$ & ND & ND & $\mathrm{ND}$ \\
\hline \multicolumn{2}{|l|}{ Soybean oil } & ND & ND & ND & ND & ND & 0.02 & ND & ND \\
\hline \multicolumn{2}{|l|}{ Rapeseed oil } & $\mathrm{ND}$ & $\mathrm{ND}$ & $\mathrm{ND}$ & 0.02 & $\mathrm{ND}$ & 0.06 & $\mathrm{ND}$ & 0.88 \\
\hline \multirow{4}{*}{ Sesame oil } & $\mathrm{A}$ & ND & ND & 0.03 & 0.05 & ND & 0.05 & ND & $\mathrm{ND}$ \\
\hline & B & $\mathrm{ND}$ & ND & $\mathrm{ND}$ & $\mathrm{ND}$ & ND & ND & $\mathrm{ND}$ & ND \\
\hline & $\mathrm{C}$ & $\mathrm{ND}$ & $\mathrm{ND}$ & $\mathrm{ND}$ & $\mathrm{ND}$ & $\mathrm{ND}$ & $\mathrm{ND}$ & $\mathrm{ND}$ & $\mathrm{ND}$ \\
\hline & $\mathrm{D}$ & ND & ND & ND & $\mathrm{ND}$ & $\mathrm{ND}$ & $\mathrm{ND}$ & $\mathrm{ND}$ & ND \\
\hline \multicolumn{2}{|c|}{ Coconut oil } & 0.42 & $\mathrm{ND}$ & $\mathrm{ND}$ & 0.02 & $\mathrm{ND}$ & 0.05 & ND & $\mathrm{ND}$ \\
\hline \multicolumn{2}{|l|}{ Cacao butter } & 1.12 & $\mathrm{ND}$ & 0.04 & 0.04 & ND & 0.57 & ND & 0.58 \\
\hline \multicolumn{2}{|l|}{ Lard } & $\mathrm{ND}$ & $\mathrm{ND}$ & 0.02 & 0.02 & ND & 0.10 & $\mathrm{ND}$ & $\mathrm{ND}$ \\
\hline \multicolumn{2}{|l|}{ Butter } & $\mathrm{ND}$ & $\mathrm{ND}$ & 0.03 & 0.02 & $\mathrm{ND}$ & 0.40 & ND & 0.24 \\
\hline
\end{tabular}

* Not detected

が検出されたものもあった. なおココナッツ油およびカ カオ脂からは, 鉛が少量検出された.

\section{5. 要 約}

食用油中の金属の定量分析に沶いて，その前処理方法 として，低温灰化装置による方法を検討した。すなわ ち，試料油脂の灰化を促進するための各種の添加剤の優 劣を比較検討した結果, 添加剂としては, 次の条件を満 たす必要がある。

1）油の表面積を増大させ，しかも油とともに灰化し 得るものであること.

2）金属含量ができるだけ少ないこと

以上の条件を満足するものとして，コーンスターチを 添加して前処理することにより，負誤差の大きかったヒ 素抢よび有機スズ中のスズが測定可能となり，他の金属 についても比較的短時間で，測定することが可能となっ た.

\section{文献}

1) Hoover, W.L., Reagor, J.C.: J. Assoc. offic. Anal. Chem., 52, 708 (1969).

2) Robert, A.I., William, W.W.: ibid., 58, 436 (1975).

3) 鈴木正己：“原子吸光分析の実際”, p. 130 (1973) 化学の領域・増刊 100 号.

4）武内次夫，鈴木正己：“原子吸光分光分析”, p. 163 (1969).

5) 日本薬学会編：“衛生試験法注解”， p. 269 (1973) 金原出版.

6) Dalton, E. F., Malanosky, A. J.: J. Assoc. Offic. Anal. Chem., 52, 1035 (1969).

7) Christian, G.D.: Anal. Chem., 41, 24 A (1969).

8) Gorsuch, T.T.: Analyst, 84, 135 (1959).

9) Brodnitz, M. H., Nawar, W. W., Fagerson, I. S.: Lipids, 3, 59 (1968). 